\title{
Persistent increase in alpha-fetoprotein level in a patient without underlying liver disease who underwent curative resection of hepatocellular carcinoma. A case report and review of the literature
}

\author{
Isidoro Di Carlo ${ }^{1 *}$, Maurizio Mannino ${ }^{1}$, Adriana Toro $^{1}$, Annalisa Ardiri ${ }^{2}$, Antonio Galia ${ }^{3}$, Giovanni Cappello ${ }^{1}$ \\ and Gaetano Bertino ${ }^{2}$
}

\begin{abstract}
Introduction: Alpha-fetoprotein (AFP) is an oncofetal protein produced by hepatocellular carcinoma (HCC). AFP level can also be elevated in other neoplastic or non-neoplastic conditions. An elevated AFP level has high diagnostic significance for $\mathrm{HCC}$; at a level of $>200 \mathrm{ng} / \mathrm{mL}$, the probability of $\mathrm{HCC}$ is $>90 \%$. The aim of the present paper is to report a patient who underwent curative resection of HCC, who had a persistently elevated AFP level postoperatively but did not develop recurrence during a 2-year follow-up period. A review of the literature is also presented.
\end{abstract}

Case report: An 82-year-old male was referred following a computed tomography scan showing a $160 \mathrm{~mm}$ diameter mass in the left lobe of the liver. This huge mass was diagnosed as HCC, arising in the absence of cirrhosis or viral hepatitis. After tumor removal, the patient's high AFP level persisted for 2 years.

Conclusion: As steatosis was the only pathological change in the remnant liver, this may have caused the persistently elevated AFP level in this patient.

Keywords: Alpha-fetoprotein, Hepatectomy, HCC without cirrhosis, HCC

\section{Background}

Hepatocellular carcinoma (HCC) is commonly associated with hepatitis $\mathrm{B}$ or $\mathrm{C}$ virus infection, and is particularly frequent in patients with cirrhosis [1]. HCC arising in a normal liver without cirrhosis or hepatitis is rare, with few reports in the literature [2-4].

HCC causes 1 million deaths every year, making it the fifth most common malignancy worldwide, and the incidence is increasing [5-8]. The current standard of care in patients with cirrhosis includes HCC screening with six-monthly measurements of alpha-fetoprotein (AFP) level together with abdominal ultrasonography or computed tomography $(\mathrm{CT})$ [9]. AFP is an oncofetal protein produced by HCC, but AFP

\footnotetext{
* Correspondence: idicarlo@unict.it

'Department of Surgical Sciences, Organ Transplantation and Advanced Technologies, University of Catania, Cannizzaro Hospital, Catania, Italy Full list of author information is available at the end of the article
}

level can also be elevated in other neoplastic or non-neoplastic conditions $[1,10,11]$. An elevated AFP level has high diagnostic significance for HCC. When the AFP level is $>200 \mathrm{ng} / \mathrm{mL}$, the probability of HCC is $>90 \%$ [12].

If the tumor is resectable, surgery is considered to be the curative treatment choice $[5,13]$. Postoperative recurrence is common, and measurement of AFP level is considered to be an extremely important screening test for the early detection of recurrence [14].

The aim of the present paper is to report a patient with a normal liver who underwent curative resection of HCC, followed by a persistently elevated AFP level during two years of follow-up without recurrence. A review of the literature is also presented.

\section{Case presentation}

An 82-year-old male was referred to us after CT scanning showed a $160 \mathrm{~mm}$ diameter mass in the left lobe of the 
liver (Figure 1). The mass compressed the stomach and displaced the gallbladder laterally. He was diagnosed with $\mathrm{HCC}$, arising in the absence of cirrhosis or viral hepatitis.

In 2007, he underwent his first CT scan, which showed hepatic steatosis and a normal-sized liver without focal lesions. In 2009, he was diagnosed with non-Hodgkin's lymphoma which was treated with allopurinol, pyridoxine, and folinic acid.

In March 2009, he underwent the CT scan, which showed the hepatic mass and resulted in his referral to us. Magnetic resonance imaging was performed in April 2009, and showed an enlarged liver with a 168 $\mathrm{mm}$ mass in segments 2 and 3 . He was diagnosed with HCC, and surgery was scheduled. He was in good nutritional condition, with no ascites or coagulopathy. Preoperative serum bilirubin and albumin levels were normal, and AFP level was $21 \mathrm{ng} / \mathrm{mL}$ (normal 0 to $7.22 \mathrm{ng} / \mathrm{mL}$ ). He underwent open resection in April 2009. The tumor occupied all of liver segments 2 and 3 , and was adherent to the stomach. The right lobe of the liver was normal in appearance. A left hepatic lobectomy was performed. Histological examination of the surgical specimen showed hepatocellular carcinoma with a solid trabecular pattern, and thick fibrotic septa which extended into the normal hepatic tissue at the resection margin (Figure 2). There was diffuse steatosis of the surrounding liver parenchyma (Figure 3).

In August 2009, at the first postoperative follow-up, his serum AFP level was $16 \mathrm{ng} / \mathrm{mL}$. Abdominal CT and positron emission tomography (PET) scans showed no evidence of tumor recurrence. Serum AFP levels were $15.7 \mathrm{ng} / \mathrm{mL}$ in November 2009 and $8.6 \mathrm{ng} /$ $\mathrm{mL}$ in February 2010. A CT scan in March 2010 and PET scan in April 2010 did not show any evidence of recurrence. AFP levels were $17.2 \mathrm{ng} / \mathrm{mL}$ in May 2010; $18.4 \mathrm{ng} / \mathrm{mL}$ in September 2010; $15.4 \mathrm{ng} / \mathrm{mL}$ in December 2010; $16.2 \mathrm{ng} / \mathrm{mL}$ in March 2011; $3.69 \mathrm{ng} / \mathrm{mL}$ in June 2011; $3.58 \mathrm{ng} / \mathrm{mL}$ in September 2011; and $3.4 \mathrm{ng} / \mathrm{ml}$ in December 2011 (Figure 4). The patient was investigated for other conditions that might cause elevated AFP levels. Testicular, gastric, pancreatic, biliary and lung cancer, and spherocytosis and tyrosinemia, were excluded.

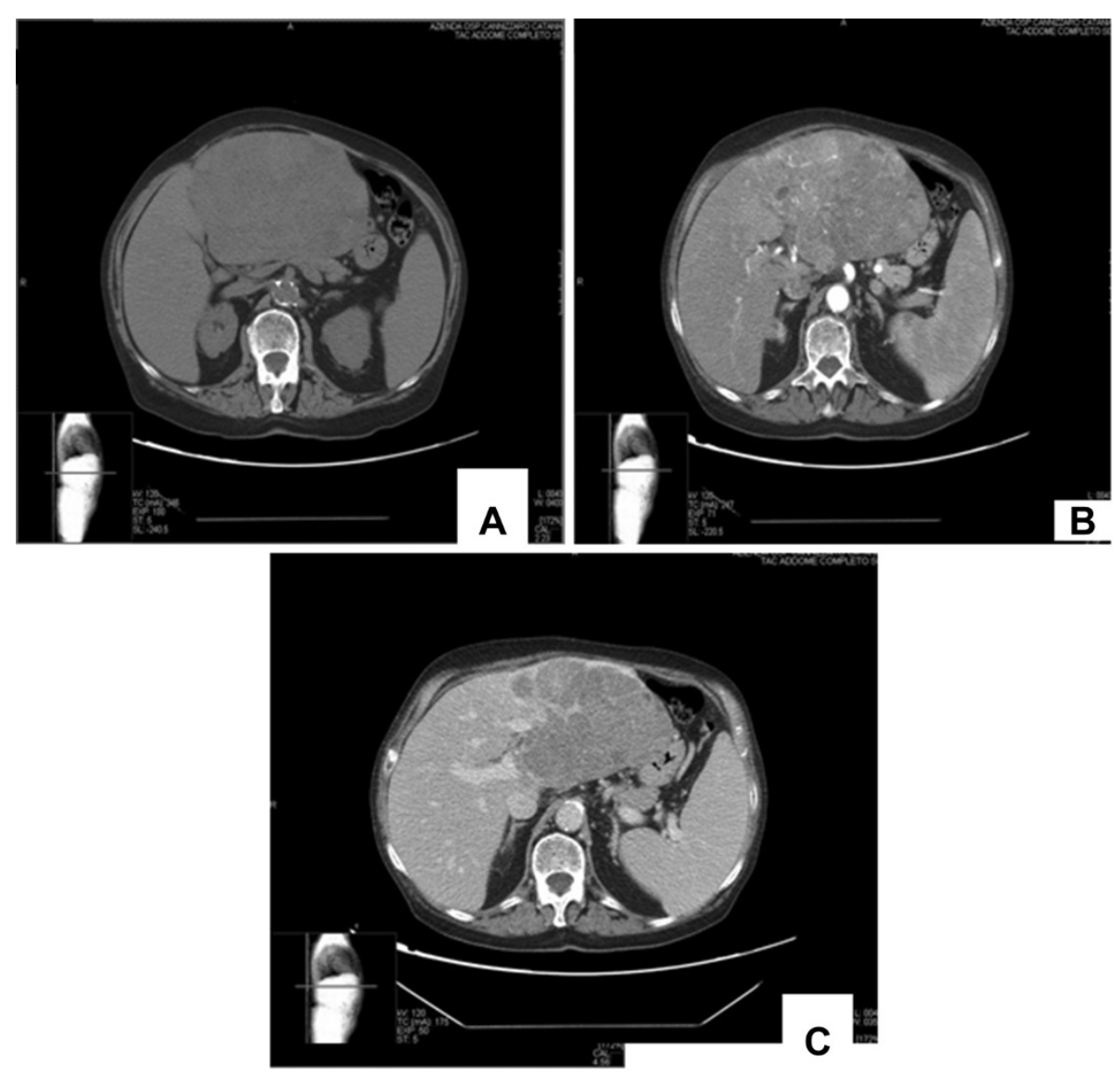

Figure 1 Computed tomography scan of the tumor in liver segments 2 and 3. (A) Pre-contrast phase; (B) Arterial phase; (C) Portal phase. 


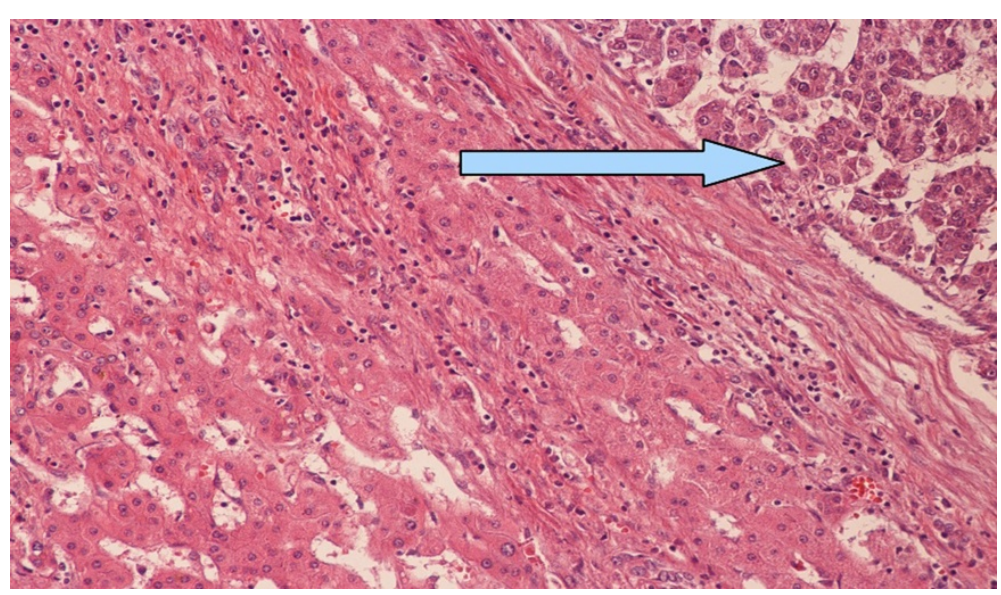

Figure 2 Upper right corner: hepatocellular carcinoma (arrow). Left: preserved laminar hepatic architecture with mild perisinusoidal lymphocytic infiltration.

\section{Discussion}

AFP is an oncofetal protein of approximately $72 \mathrm{kDa}$. AFP is produced by normal gastrointestinal cells, yolk sac cells, and fetal hepatocytes immediately after birth. Serum AFP level decreases gradually after birth, to $<10 \mathrm{ng} / \mathrm{mL}$ within 300 days [15]. Some reports indicate that healthy individuals may have AFP levels of up to $20 \mathrm{ng} / \mathrm{mL}$, and levels above this are considered to indicate the possibility of liver disease [16]. The normal range is given as 0 to $7.22 \mathrm{mg} /$ $\mathrm{mL}$ in our laboratory and, in the current case, the AFP level was persistently above this range.

AFP level may be elevated in patients with chronic liver disease such as hepatitis or cirrhosis, or patients with drug or alcohol abuse, but in these cases the level is usually $<100 \mathrm{ng} / \mathrm{mL}[11,17]$. The presence of a focal hypervascular lesion $>2 \mathrm{~cm}$ in diameter associated with a serum AFP level of $>400 \mathrm{ng} / \mathrm{mL}$ is considered diagnostic for HCC [18]. The Italian and the American Association for the Study of Liver Diseases guideline considers an AFP level of $\geq 200 \mathrm{ng} / \mathrm{mL}$ to be diagnostic for HCC [11] .

AFP level is used for both early diagnosis and monitoring of $\mathrm{HCC}$, but it is estimated that the false-negative rate when using AFP level as a single parameter may be as high as $40 \%$, especially in patients with early HCC. AFP level may remain in the normal range in 15 to $30 \%$ of patients with HCC [19]. A high preoperative AFP level is associated with intrahepatic metastasis, early recurrence, and a poor survival rate after hepatectomy. The ratio of AFP level to tumor diameter may be a better

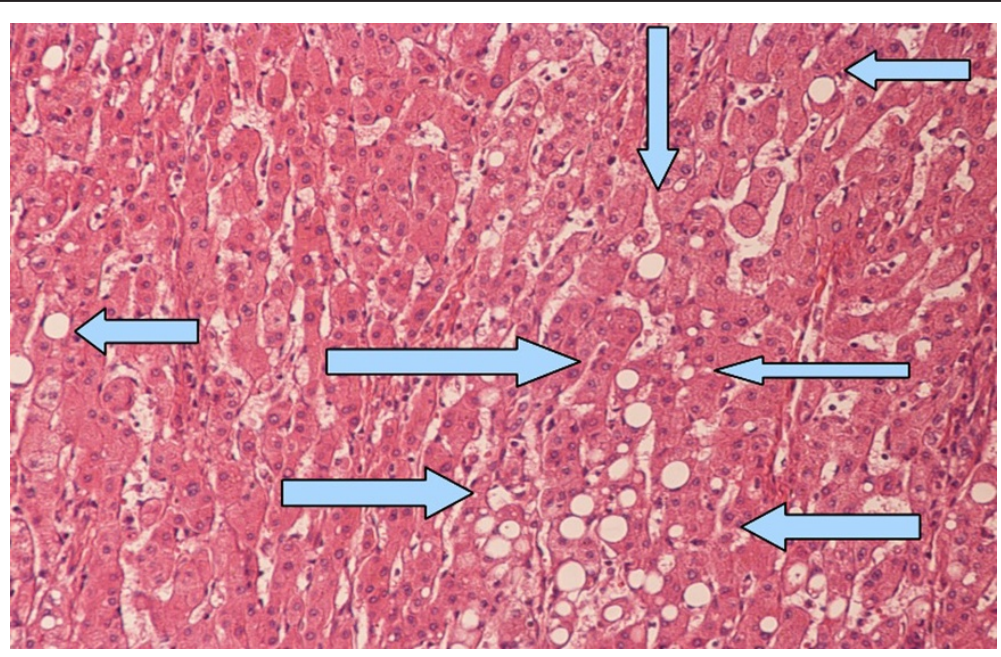

Figure 3 Normal hepatic tissue with diffuse steatosis (arrows). 


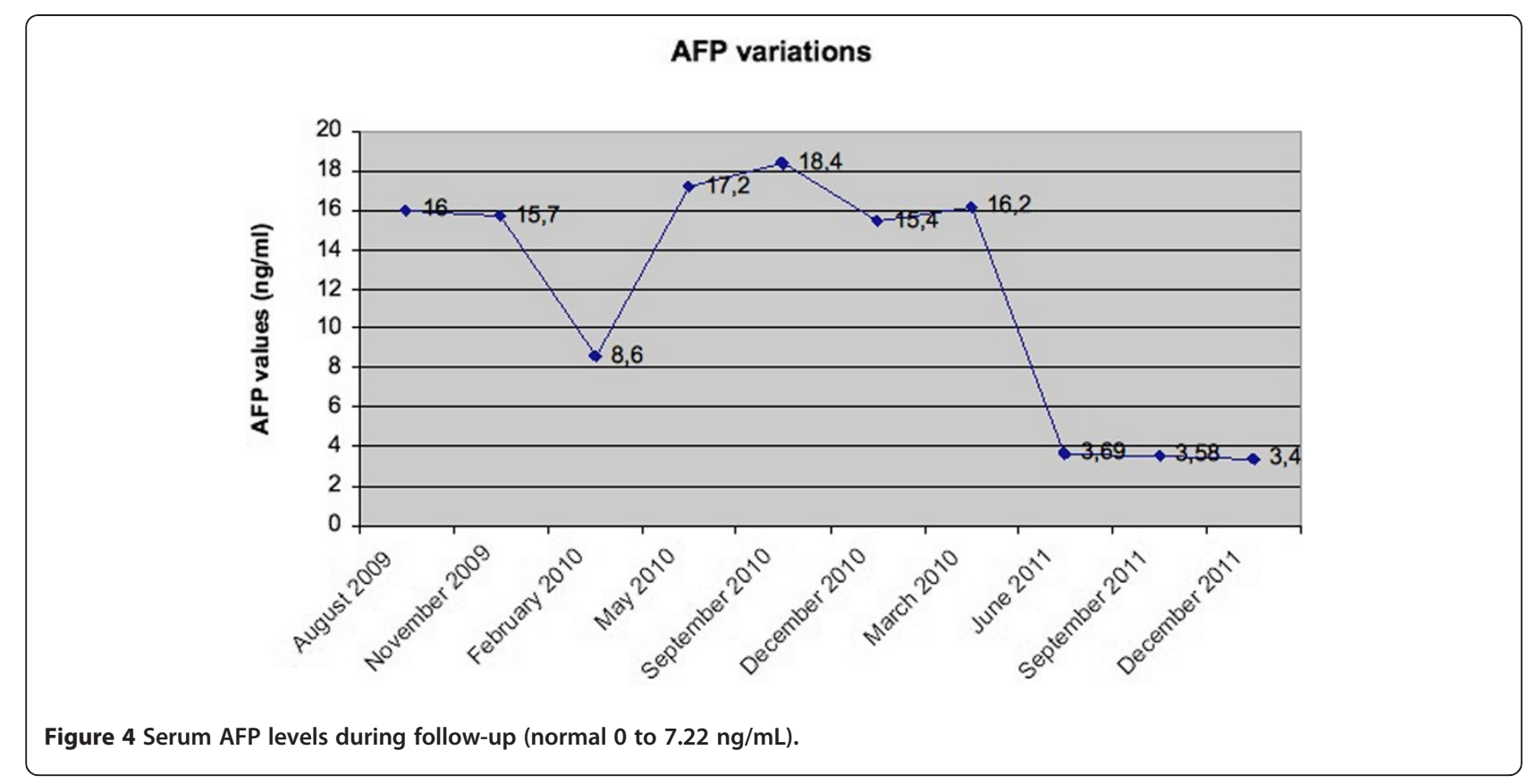

predictor of recurrence after curative resection than serum AFP level alone [20].

AFP level can be used for postoperative monitoring, especially when it is elevated in the early postoperative period. Recurrent HCC is expected to have the same bioactivity as the primary tumor. Some patients with an elevated AFP level at initial HCC presentation do not have an elevated level with recurrence; this may be because the recurrence is actually a second primary tumor with chromosomal aberration [21].

Exacerbation of infectious hepatitis or cirrhosis may also cause a transiently elevated AFP level [22].

AFP levels vary during the different phases of the underlying disease, but do not follow a regular pattern. As AFP levels vary between patients and diseases, it is possible that two patients with the same disease, who are in the same phase of disease progression, have differences in their AFP levels; one could have an elevated AFP level, while the other could have an AFP level close to zero [11,22].

The persistently elevated AFP level after hepatectomy in the current patient cannot be explained by exacerbation of an underlying disease, because he did not have hepatitis or cirrhosis. Incomplete resection of the tumor margins might be suspected, but pathological examination showed adequate margins, and curative resection was confirmed by the absence of recurrence on CT and PET scans.

As well as being produced by the tumor, AFP may play a role in tumor growth, as preclinical evidence has shown that AFP may have a modulatory effect on hepatoma cells [20].

Many studies have reported that an elevated AFP level is an adverse prognostic factor in both early and advanced stages of HCC. An AFP level of $>10,000 \mathrm{ng} / \mathrm{mL}$ is associated with a three-year survival rate of $40 \%$, and an AFP level of 200 to $10,000 \mathrm{ng} / \mathrm{mL}$ is associated with a threeyear survival rate of $70 \%$ [20]. In HCC patients with a low AFP level (20 to $100 \mathrm{ng} / \mathrm{mL}$ ), the AFP level may decrease and falsely indicate a response to treatment, due to the low specificity of AFP for HCC in this range [20].

AFP levels are useful for evaluating the response to treatment and for detecting recurrence [11]. In cases of HCC arising in a liver without cirrhosis or viral hepatitis, these variations can be more evident, and normal cut-off values may be lower. Lubrano et al. [3] reported a study of 20 patients with this rare presentation of HCC, and found that only half had elevated AFP levels. As the current patient had the same type of disease as those evaluated in the study by Lubrano et al., his persistently elevated AFP level after hepatectomy, which was above the normal range but not as high as the cut-off value, was particularly suspicious for recurrent $\mathrm{HCC}$ and had to be carefully evaluated.

Although the literature describing HCC arising in a liver without cirrhosis or viral hepatitis is inconsistent, existing studies do agree on some aspects of this disease. The most important aspect is the difference between the natural courses of HCC arising in normal liver parenchyma and in cirrhotic liver. Liver cirrhosis and portal hypertension result in a reduced survival rate in $\mathrm{HCC}$ patients, especially those treated in the early stage of the disease (TNM stage I) $[2,3,23]$. It has also been reported that HCC in non-cirrhotic livers is more frequent in men than in women, and that the tumors are larger than those in cirrhotic livers $[3,23]$. In patients with HCC arising in both non-cirrhotic and cirrhotic livers, the main cause of postoperative death is 
cancer recurrence, which usually occurs within two years after surgery [23].

The frequency of postoperative recurrence is similar in patients with hepatitis $\mathrm{B}$ or $\mathrm{C}$ virus infection and those without, but patients without chronic hepatitis have better liver function and tend to get fewer nodules in the remnant liver, which enables easier resection of recurrences [4].

Extensive resection with a wide tumor margin is technically easier in HCC arising in a non-cirrhotic liver than a cirrhotic liver, resulting in a lower probability of recurrence and a better prognosis [23-26].

Elevated AFP level is not always associated with liver disease. Other conditions (neoplastic or non-neoplastic) can also cause a transient or persistent elevation in APF level, and should be considered in the differential diagnosis. Non-seminoma testis cancer can cause an elevated AFP level in association with elevated levels of other tumor markers such as beta-human chorionic gonadotropin and lactate dehydrogenase $[27,28]$. A pure seminoma may also produce AFP, but should then be managed as a non-seminoma cancer [28]. Approximately 2 to $6 \%$ of gastric cancers produce AFP, and these are generally associated with high rates of venous invasion, lymph node metastasis and liver metastasis, and an extremely poor survival rate, compared with other gastric cancers [29]. Hepatoid carcinoma is a primary extrahepatic neoplasm that has similar features to HCC in terms of immunohistochemistry, morphology, and biological behavior. Many patients with hepatoid carcinoma have an elevated serum AFP level at presentation. These tumors most commonly arise in the stomach, but a small proportion arise in the pancreas [30]. Approximately $2 \%$ of lung cancers produce AFP. AFP-producing lung cancers are usually adenocarcinomas, with a small proportion being large-cell carcinomas and squamous-cell carcinomas [31].

Pregnancy may cause an elevated AFP level, especially when the pregnancy is complicated by an abnormality such as a spinal cord defect [32].

Obesity and diabetes seem to be associated with HCC. These conditions are risk factors for cirrhosis, but their role in the non-cirrhotic liver is more controversial [26].

Hepatic steatosis can also cause a high AFP level. Steatosis can be divided into two phases; during the first phase, lipids accumulate in the hepatocytes, and in the second phase, factors such as oxidative stress, proinflammatory cytokines, mitochondrial dysfunction, and lipid peroxidation damage the hepatocytes and cause inflammation and fibrosis. In 2009, a study by Babali et al. [33] found that AFP level was associated with the grade of steatosis. In patients with steatosis, AFP production may be stimulated by cytokines, or may result from altered interactions between hepatocytes [33].

In our patient, steatosis was the only abnormality of the hepatic parenchyma detected on pathological examination, and was the only condition that could have caused the persistently elevated AFP level, as laboratory tests and imaging results eliminated all other possible causes.

Non-alcoholic steatohepatitis (NASH) can induce HCC by unknown mechanisms, in which insulin resistance seems to play an important role. Insulin resistance causes inhibition of hepatic mitochondrial fatty acid oxidation and stimulation of microsomal peroxidases, resulting in increased intracellular concentrations of fatty acids, which may cause oxidative DNA damage [34].

NASH can evolve into cirrhosis before giving rise to HCC, but the cirrhosis stage is not necessary, as there are many reported cases in the literature of HCC arising directly from NASH. NASH therefore has to be considered as a possible cause when HCC arises in a non-cirrhotic liver [34,35]. HCC arising in NASH may occur without an elevated AFP level [36].

Another rare condition that may cause an elevated AFP level in a patient with a normal liver is hereditary persistence of AFP (HPAFP), which is asymptomatic. Only 19 families with HPAFP have been described over the past 28 years, many of whom also had urological disorders (malignant or benign). HPAFP can, therefore, also be considered in patients with an unexplained high AFP level $[37,38]$.

\section{Conclusions}

In conclusion, we present a case in which hepatic steatosis is the only possible cause of the persistently elevated AFP level after curative resection of HCC.

\section{Consent}

Written informed consent was obtained from the patient for publication of this case report and any accompanying images. A copy of the written consent is available for review by the Editor-in-Chief of this journal.

\section{Abbreviations \\ AFP: Alpha-fetoprotein; CT: Computed tomography; HCC: Hepatocellular carcinoma; NASH: Non-alcoholic steatohepatitis; PET: Positron emission tomography; HPAFP: Hereditary persistence of alpha-fetoprotein.}

\section{Competing interests}

All authors declare that they have no competing interests.

\section{Author details}

${ }^{1}$ Department of Surgical Sciences, Organ Transplantation and Advanced Technologies, University of Catania, Cannizzaro Hospital, Catania, Italy.

${ }^{2}$ Department of Internal Medicine and Systemic Disease, Hepatology Unit, University of Catania, S. Marta Hospital, Via Messina 829, 95126 Catania, Italy. ${ }^{3}$ Department of Pathology, Cannizzaro Hospital, Via G. Clementi 36, 95124 Catania, Italy.

\section{Authors' contributions}

IDC was the principle investigator who prepared, organized, and edited all aspects of the manuscript, and the surgeon who performed the operation. MM supported the work of the principle investigator in writing and editing the manuscript. AT supported the work of the principle investigator in writing and editing the manuscript. AA supported the work of the principle investigator in preparing the manuscript. AG was the pathologist who performed the pathological examination of the surgical specimen. GC 
supported the work of the principle investigator in preparing the manuscript. GB supported the work of the principle investigator in preparing the manuscript. All authors read and approved the final manuscript.

Received: 13 February 2012 Accepted: 6 May 2012

Published: 6 May 2012

\section{References}

1. Tsai JF, Jeng JE, Ho MS, Chang WY, Lin ZY, Tsai JH: Clinical evaluation of serum alpha-fetoprotein and circulating immune complexes as tumour markers of hepatocellular carcinoma. Br J Cancer 1995, 72:442-446.

2. Lang H, Sotiropoulos GC, Dömland M, Frühauf NR, Paul A, Hüsing J, Malagò M Broelsch CE: Liver resection for hepatocellular carcinoma in non-cirrhotic liver without underlying viral hepatitis. Br J Surg 2005, 92:198-202.

3. Lubrano J, Huet E, Tsilividis B, François A, Goria O, Riachi G, Scottè M: Long-term outcome of liver resection for hepatocellular carcinoma in noncirrhotic nonfibrotic liver with no viral hepatitis or alcohol abuse. World J Surg 2008, 32:104-109.

4. Yokoi Y, Suzuki S, Baba SK, Inaba K, Konno H, Nakamura S: Clinicopathological features of hepatocellular carcinomas (HCCs) arising in patients without chronic viral infection or alcohol abuse: a retrospective study of patients undergoing hepatic resection. $J$ Gastroenterol 2005, 40:274-282

5. Hao K, Luk JM, Lee NP, Mao M, Zhang C, Ferguson MD, Lamb J, Dai H, Ng $I O$, Sham PC, Poon RT: Predicting prognosis in hepatocellular carcinoma after curative surgery with common clinicopathologic parameters. BMC Cancer 2009, 9:389.

6. Bosch FX, Ribes J, Borras J: Epidemiology of primary liver cancer. Semin Liver Dis 1999, 19:271-285.

7. Kim JH, Choi MS, Lee H, Kim do Y, Lee JH, Koh KC, Yoo BC, Paik SW, Rhee $\mathrm{JC}$ : Clinical features and prognosis of hepatocellular carcinoma in young patients from a hepatitis B-endemic area. J Gastroenterol Hepatol 2006, 21:588-594

8. Lam WW, Ng KK, Chok KS, Cheung TT, Yuen J, Tung H, Tso WK, Fan ST, Poon RT: Risk factors and prognostic factors of local recurrence after radiofrequency ablation of hepatocellular carcinoma. J Am Coll Surg 2008, 207:20-29.

9. Corey KE, Pratts DS: Current status of therapy for hepatocellular carcinoma. Therap Adv Gastroenterol 2009, 2:45-57.

10. Sherman M: Current status of alpha-fetoprotein testing. Gastroenterol Hepatol (NY) 2011, 7:113-114

11. Arrieta O, Cacho B, Morales-Espinosa D, Ruelas Villavicencio A, Flores-Estrada $D$, Hernàndez-Pedro N: The progressive elevation of alpha-fetoprotein for the diagnosis of hepatocellular carcinoma in patients with liver cirrhosis. BMC Cancer 2007, 7:28.

12. Gervain J: Symptoms of hepatocellular carcinoma. Laboratory tests used for its diagnosis and screening. Orv Hetil 2010, 151:1415-1417.

13. Lau WY, Lai EC: Hepatocellular carcinoma: current management and recent advances. Hepatobiliary Pancreas Dis Int 2008, 7:237-757.

14. Shirabe K, Takenaka K, Gion T, Shimada M, Fujiwara Y, Sugimachi K: Significance of alpha-fetoprotein levels for detection of early recurrence of hepatocellular carcinoma after hepatic resection. J Surg Oncol 1997, 64:143-146

15. Zhou YM, Yang JM, Li B, Yin ZF, Xu F, Wang B, Xu W, Kan T: Risk factors for early recurrence of small hepatocellular carcinoma after curative resection. Hepatobiliary Pancreas Dis Int 2010, 9:33-37.

16. Eleftheriou N, Heathcote J, Thomas HC, Sherlock S: Serum alpha-fetoprotein levels in patients with acute and chronic liver disease. Relation to hepatocellular regeneration and development of primary liver cell carcinoma. J Clin Pathol 1977, 30:704-708.

17. Van der Veek PP, de Vos Tot Nederveen Cappel WH, Langers AM, van Hoek B: Two patients with extremely elevated tumor markers: where is the malignancy? Gastroenterol Res Pract 2011;123743.

18. Farinati F, Marino D, De Giorgio M, Baldan A, Cantarini M, Cursaro C, Rapaccini G, Del Poggio P, Di Nolfo MA, Benvegnù L, Zoli M, Borzio F, Bernardi M, Trevisani F: Diagnostic and prognostic role of alpha-fetoprotein in hepatocellular carcinoma: both or neither? Am J Gastroenterol 2006, 101:524-532.

19. Yao DF, Dong ZZ, Yao M: Specific molecular markers in hepatocellular carcinoma. Hepatobiliary Pancreas Dis Int 2007, 6:241-247.
20. Chan SL, Chan AT, Yeo W: Role of alpha-fetoprotein in hepatocellular carcinoma: prognostication, treatment monitoring or both? Future Oncol 2009, 5:889-899.

21. Hsieh CB, Chen TW, Chu CM, Chu HC, Yu CP, Chung KP: Is inconsistency of alpha-fetoprotein level a good prognosticator for hepatocellular carcinoma recurrence? World J Gatroenterol 2010, 16:3049-3055.

22. Pateron D, Ganne N, Trinchet JC, Aurousseau MH, Mal F, Meicler C, Coderc E, Reboullet $\mathrm{P}$, Beaugrand M: Prospective study of screening for hepatocellular carcinoma in Caucasian patients with cirrhosis. $J$ Hepatol 1994, 20:65-71.

23. Chang $\mathrm{CH}$, Chau GY, Lui WY, Tsay Sh, King KL, Wu CW: Long-term results of hepatic resection for hepatocellular carcinoma originating from the noncirrhotic liver. Arch Surg 2004, 139:320-325.

24. Chau GY, Lui WY, Tsay SH, King KL, Loong CC, Chiu JH, Wu CW, P'eng FK: Prognostic significance of surgical margin in hepatocellular carcinoma resection: an analysis of 165 Childs' A patients. J Surg Oncol 1997, 66:122-126.

25. Takano S, Oishi H, Kono S, Kawakami S, Nakamura M, Kubota N, Iwai S: Retrospective analysis of type of hepatic resection for hepatocellular carcinoma. Br J Surg 2000, 87:65-70.

26. Alkofer B, Lepennec $V$, Chiche L: Hepatocellular cancer in the non-cirrhotic liver. J Visc Surg 2011, 148:3-11

27. Toonen F, Smilde T: A retroperitoneal mass with elevated alpha-1-fetoprotein: not always a testicular carcinoma. Neth J Med 2010, 68:33-34

28. Schmoll HJ, Jordan K, Huddart R, Pes MP, Horwich A, Fizazi K, Kataja V: Testicular seminoma: ESMO clinical practice guidelines for diagnosis, treatment and follow-up. Ann Oncol 2010, 21:147-154.

29. Kanda T, Yoshida H, Mamada Y, Taniai N, Kawano Y, Mizuguchi Y, Shimizu T, Takahashi T, Ueda J, Kato S, Akimaru K, Tajiri T, Fukuda Y: Resection of liver metastases from an alpha-fetoprotein-producing gastric cancer. J Nihon Med Sch 2005, 72:66-70.

30. Liu CZ, Hu SY, Wang L, Zhi XT, Jin B, Zhu M, Wachtel MS, Frezza EE: Hepatoid carcinoma of the pancreas: a case report. Chin Med J (Engl) 2007, 120:1850-1852

31. Kitada M, Ozawa K, Sato K, Matsuda Y, Hayashi S, Tokusashi Y, Miyokawa N, Sasajima T: Alpha-fetoprotein-producing primary lung carcinoma: a case report. World J Surg Oncol 2011, 9:47.

32. Perkins GL, Slater ED, Sanders GK, Prichard JG: Serum tumor markers. Am Fam Physician 2003, 68:1075-1082.

33. Babali A, Cakal E, Purnak T, Biyikoĝlu I, Cakal B, Yüksel O, Köklü S: Serum alpha-fetoprotein levels in liver steatosis. Hepatol Int 2009. doi:10.1007/ s12072-009-9156-8. Nov 5.

34. Takuma Y, Nouso K: Nonalcoholic steatohepatitis-associated hepatocellular carcinoma: our case series and literature review. World J Gastroenterol 2010, 16:1436-1441.

35. Wree A, Kahraman A, Gerken G, Canbay A: Obesity affects the liver - the link between adipocytes and hepatocyte. Digestion 2011, 83:124-133.

36. Chagas AL, Kikuchi LO, Oliveira JP, Vezozzo DC, Mello ES, Oliveira AC, Cella LC, Herman P, Bachella T, Caldwell SH, Alves VA, Carrilho FJ: Does hepatocellular carcinoma in non-alcoholic steatohepatitis exist in cirrhotic and non-cirrhotic patients? Braz J Med Biol Res 2009, 42:958-962

37. Houwert AC, Giltay JC, Lentjes EG, Lock MT: Hereditary persistence of alpha-fetoprotein (HPAFP): review of the literature. Neth J Med 2010 68:354-358

38. No authors listed: Program of the annual meeting of the American Gastroenterology Association for the Study of Liver Diseases, and the Gastroenterology Study Group. Abstracts of Papers. Gastroenterology 1979, 76:1089-1316

doi:10.1186/1477-7819-10-79

Cite this article as: Di Carlo et al: Persistent increase in alpha-fetoprotein level in a patient without underlying liver disease who underwent curative resection of hepatocellular carcinoma. A case report and review of the literature. World Journal of Surgical Oncology 2012 10:79. 